\title{
Effects of Habitual Moderate Exercise on Response Processing and Cognitive Processing in Older Adults
}

\author{
Arihiro HATTA, Yoshiaki NISHIHIRA, Seung Ryol KIM*, Takeshi KANEDA, Tetsuo KIDA, \\ Keita KAMIJO*, Michiko SASAHARA ${ }^{\dagger}$, and Shuko HAGA \\ Graduate School of Comprehensive Human Sciences, *Doctoral Program in Graduate School of \\ Comprehensive Human Sciences, and Master Program in Physical Education, University of Tsukuba, \\ Tsukuba, 305-8574 Japan
}

\begin{abstract}
We examined the effects of habitual moderate exercise on central information processing in older individuals using the reaction time (RT) and P3 component of event-related brain potentials (ERP). The present study was designed to assess cognitive function by comparing groups of 20 older individuals (69.20 \pm 1.3 years active group) who regularly engage in moderate physical activity with 20 subjects (66.90 \pm 1.1 years inactive group) who do comparatively little exercise. Subjects performed a somatosensory oddball task composed of pressing a button with their right foot as fast as possible following an electrical stimulus applied to the right index finger, and not responding to an electrical stimulus applied to the left index finger.
\end{abstract}

Electroencephalogram (EEG) was recorded at the frontal $(\mathrm{Fz})$, central $(\mathrm{Cz})$, and parietal $(\mathrm{Pz})$ sites according to the International 10-20 system referenced to linked earlobes. The RT was faster for the active group than for the inactive group, and the P3 amplitude of the active group was significantly larger than that of the inactive group. Moreover, the P3 amplitude for the active group was maximum at $\mathrm{Pz}$ and significantly larger than at $\mathrm{Fz}$ and $\mathrm{Cz}$, but for the inactive group it was identical between $\mathrm{Fz}$ and $\mathrm{Pz}$. The results suggest that habitual moderate exercise exerts positive influences in older adults not only on response processing, but also on cognitive processing. [The Japanese Journal of Physiology 55: 29-36, 2005]

Key words: aging, moderate exercise, information processing, P3, ERP.

Physiological functional capacity declines at some point with advancing age even in healthy adults, resulting in a reduced capacity to perform certain physical tasks [1]. For example, reaction time (RT) and movement time experiments revealed that older adults always respond slower than younger individuals $[2,3]$. In normal aging, the human brain begins to lose tissue early in the third decade of life. Average losses are estimated at roughly $15 \%$ of the cerebral cortex and $25 \%$ of the cerebral white matter between the ages of 30 to $90[4,5]$. Furthermore, normal aging is associated with changes in electroencephalogram (EEG) and the P3 component of event-related brain potentials (ERP), which reflects cognitive processing [6]. P3 latency has been considered an index of stimulus evaluation $[7,8]$ or classification speed [9], and P3 amplitude is proportional to the amount of attentional resources [10] or context updating of working memory resources [11]. With age, P3 latency consistently increases and P3 amplitude usually decreases and becomes more evenly distributed over the scalp $[12,13]$. Moreover, both cognitive processes and motor responses slow as individuals get older [3,6].

On the other hand, long-term physical exercise results in adaptations of the neuromuscular [14], metabolic [15], cardiovascular [16], and endocrine systems [17]. It has also been reported that these adaptive changes occur in older adults $[15,18]$. The results of cross-sectional studies of humans are also in agreement with the notion that the RT has typically been

Received on September 7, 2004; accepted on January 28, 2005; DOI: 10.2170/jjphysiol.R2068

Correspondence should be addressed to: Arihiro Hatta, Graduate School of Comprehensive Human Sciences, University of Tsukuba,

1-1-1 Tennodai, Tsukuba, 305-8574 Japan. Tel/Fax: +81-298-53-2769, E-mail: hatta@taiiku.tsukuba.ac.jp 
found to be shorter in physically active adults than in inactive older ones [3, 19]. Although behavioral and psychomotor measurements have been extensively employed in studies on exercise and aging of the brain, little investigation into the relationship between longterm exercise and cognitive processing in adults has occurred using electrophysiological measurements [20]. Dustman et al. [21] reported that P3 latency was faster in aerobically trained older men than in inactive ones. However, two previous studies reported no significant difference in P3 latency between high-fitness and low-fitness older adults [20, 22]. These studies, correlating the effects of long-term exercise on central information processing in older adults, have compared cognitive functions between aerobically high-fitness older participants and low-fitness ones. However, high-intensity or heavy exercise such as aerobic highfitness training is not appropriate for older adults.

Moderate- and light-intensity activities, such as walking for pleasure, gardening, housework, and slow dancing belong to normal everyday life, and have been demonstrated to produce significant long-term health benefits and to lower the risk of cardiovascular events [23]. Regular physical activity positively influences several factors that may retard or prevent age-related cerebral atherogenesis and sustain cognitive abilities [24]. Colcombe et al. [25] suggested that increased cardiovascular fitness affects improvements in the plasticity of the aging human brain. Recently, Harada et al. [26] showed that habitual jogging improved performance in a prefrontal branching task. Furthermore, light-intensity exercise represents an important component of most clinical programs of rehabilitation [27]. Regardless of its importance, the effect of moderate- and light-intensity exercise on the central nervous system (CNS) of older adults is not fully understood. Thus, it is necessary to investigate the effect of moderate exercise on cognitive function in older individuals. The hypothesis that has guided the present study is that habitual moderate physical activity exerts beneficial influences resulting in the attenuation of cognitive function decline in older adults. We examined the effects of habitual moderate exercise on response processing and cognitive processing in older participants by the use of an ERP study.

\section{METHODS}

Subjects. Healthy right-handed individuals from the physically active and inactive groups were matched by age $(69.20 \pm 1.3$ vs. $66.90 \pm 1.1$ years $)$ and sex (10 males and 10 females in each group). Table 1 presents
Table 1. Age and anthropometric data for active and inactive older participants.

\begin{tabular}{lrr}
\hline Measurement & \multicolumn{1}{c}{ Active } & \multicolumn{1}{c}{ Inactive } \\
\hline Age (year) & $69.20 \pm 1.3$ & $66.90 \pm 1.1$ \\
Height $(\mathrm{cm})$ & $155.65 \pm 1.7$ & $158.35 \pm 2.2$ \\
Weight $(\mathrm{kg})$ & $56.30 \pm 1.5$ & $60.85 \pm 2.0$ \\
\hline
\end{tabular}

Values are means $\pm \mathrm{SE}$.

their characteristics. The active group comprised vigorous participants who had taken part in physical exercises for more than three years; the exercise consisted of one 90 min session once a week in Tsukuba City. Moreover, almost all were accustomed to walking for more than 60 minutes every day. In contrast, the inactive group, which comprised newcomers to the physical exercise class in Tsukuba City, had no history of physical exercise. They independently participated in the present study before starting the class. All subjects reported being free of neurological or psychiatric disorders and provided informed consent. The appropriate committee at the University of Tsukuba approved the experimental protocols.

Physical exercise. Trained physical educators guided the class-based multi-component exercises, which comprised movements typically involving rhythm, aerobic performance, muscle strength, flexibility, and stretching (Table 2). The muscle strength exercises were performed with the use of rubber bands or the participants' own body weight. The relative workload was estimated from the maximal heart rate, and the relative exercise intensity was approximately $60-70 \%$ during aerobic performance. The participants could rest to drink water whenever they felt tired. No accidents or medical complications that related directly to the physical exercise were observed.

Procedure. The subjects were comfortably seated in a chair, placed their right foot on and depressed a button fixed on the floor. The room was dimly lit and air-conditioned $\left(25^{\circ} \mathrm{C}\right)$. They were asked to keep their eyes open and fixated on a target placed about $1 \mathrm{~m}$ in front of them in order to eliminate blinks and slow eye movements.

Somatosensory stimuli with $0.2 \mathrm{~ms}$ duration were delivered to the index finger of each hand using a constant current stimulator through ring electrodes. The left (non-target, $80 \%$ of total) and right index finger stimuli (target, $20 \%$ of total) were randomly delivered. The interstimulus interval (ISI) varied randomly from 800 to $1,400 \mathrm{~ms}$. The stimulus intensity was adjusted to three times the individual sensory threshold (range 5.4-8.7 mA). The stimuli caused neither discomfort 
Aging, Moderate Exercise and P3

Table 2. The program at the exercise club in Tsukuba City for individuals more than 60 years old.

\begin{tabular}{lll}
\hline \multicolumn{1}{c}{ Menu } & \multicolumn{1}{c}{ Contents } & Time \\
\hline Warm-up & Rythmical step and static stretching & 20 min \\
Aerobic exercise & Movements back and forth, right and left, and combinations of them & 30 min \\
by moving the upper and lower limbs to the sound of music & \\
Muscle conditioning & $\begin{array}{l}\text { Activation of both agonist and antagonist muscles by using rubber } \\
\text { bands }\end{array}$ & \\
Stretching, relaxing, and cooling down & $\begin{array}{l}\text { Taking the stiffness out of muscles and relaxation (respiratory } \\
\text { method) }\end{array}$ & \\
\hline
\end{tabular}

nor startle reactions. A total of 150 stimuli were delivered (30 targets and 120 non-targets).

Task. Subjects performed a somatosensory oddball task composed of pressing the button with their right foot as fast as possible following an electrical stimulus to the right index finger (target), and not responding to an electrical stimulus applied to the left index finger (non-target). All subjects were instructed to minimize upper body movements and to avoid eye movements and blinking as much as possible.

Electrophysiological recording. Electroencephalogram (EEG) was recorded at $\mathrm{Fz}$ (frontal site), $\mathrm{Cz}$ (central site), and $\mathrm{Pz}$ (parietal site) according to the International 10-20 system referenced to linked earlobes. To monitor possible artifacts due to eye movements, electrooculogram (EOG) was recorded using electrodes above and below the right eye. The EEG and EOG were recorded using a digital evoked potential measuring system (Neuropack, MEB-2216, Nihon Kohden), with a filter set to a band pass of $0.1-100 \mathrm{~Hz}$.

\section{DATA ANALYSIS}

The reaction time (RT) between 250 and $800 \mathrm{~ms}$ after the stimuli was recorded as a correct response. All subjects performed the task with an error rate of less than 5\%. Somatosensory ERP was obtained with right index finger stimuli (target) and left index finger stimuli (non-target). The averages of 20 waveforms for the target and all non-target trials were analyzed for 1,000 ms, including $100 \mathrm{~ms}$ before and $900 \mathrm{~ms}$ after each electrical stimulus, respectively. The baseline for measuring the amplitude of recognizable potentials was determined by averaging the $100 \mathrm{~ms}$ just before each electrical stimulus presentation. Trials with eye blinking (EOG greater than $\pm 50 \mu \mathrm{V}$ ), movement artifacts (EEG greater than $\pm 100 \mu \mathrm{V}$ ) and response errors were excluded from the averaging. Waveforms from each electrode and stimulus condition were analyzed with the P3 component, defined as the largest positive going peak occurring for all electrode sites with a latency window from 250 to $500 \mathrm{~ms}$. The P3 amplitude was measured relative to the prestimulus baseline, with peak latency defined as the time point of maximum positive amplitude.

\section{STATISTICS}

Reaction time. Statistical comparisons for each time window from 250 to $800 \mathrm{~ms}$ after the onset of the somatosensory stimulus were made with the Fisher PLSD post hoc procedure (analysis of variance).

P3 component. A repeated measures analysis of variance was performed on the P3 component for the following variables: Group (active, inactive) $\times$ Electrode location $(\mathrm{Fz}, \mathrm{Cz}, \mathrm{Pz})$. To decrease the experiment-wise error rate due to the repeated measures design involving multiple dependent variables, a Greenhouse and Geisser adjustment of the degrees of freedom was performed. This correction was applied when the violations of sphericity for significant effects occurred in the analysis of variance with two or more degrees of freedom [28]. Post hoc testing was conducted only when preceded by a significant analysis of variance effects. Statistical significance was set at $\mathrm{p}<0.05$.

\section{RESULTS}

\section{Reaction time}

The reaction time (RT) was recorded for each run and was faster for the active group $(379.98 \pm 14.3 \mathrm{~ms})$ than for the inactive group $(432.49 \pm 15.9 \mathrm{~ms}, \mathrm{p}<$ 0.05) (Table 3).

\section{Event-related brain potential waveforms}

Figure 1 shows the averaged event-related brain potentials (ERP) recorded during a somatosensory oddball task at each scalp location. A distinct positive P3 component (250-500 ms) was identified. 


\section{A. HATTA et al.}


Fig. 1. A: 20 grand average event-related brain potentials (ERP) of somatosensory targets for the active older (thick line) and inactive older (dotted line) groups. B: 100 averaged non-target ERP waveforms. ERP was recorded at the frontal (Fz), central (Cz), and parietal (Pz) midline locations. P3: P3 component of ERP.

\section{P3 latency}

There were no significant main effects for either the Group or Electrode location, and no significant interactions between them (Table 3).

\section{P3 amplitude}

Both the Group and Electrode location showed significant main effects on the $\mathrm{P} 3$ amplitude values $\left(F_{1}\right.$,

Table 3. The analysis variance results of the main effect for reaction time, P3 latency, and amplitude for the Group type (active vs. inactive).

\begin{tabular}{lcc}
\hline \multirow{2}{*}{ Components } & \multicolumn{2}{c}{ Group } \\
\cline { 2 - 3 } & Active & Inactive \\
\hline Reaction time $(\mathrm{ms})$ & $379.98 \pm 14.3^{*}$ & $432.49 \pm 15.9$ \\
P3 latency $(\mathrm{ms})$ & $372.57 \pm 5.4$ & $364.97 \pm 4.7$ \\
P3 amplitude $(\mu \mathrm{V})$ & $11.11 \pm 0.6^{*}$ & $7.54 \pm 0.7$ \\
\hline
\end{tabular}

Values are means \pm SE. A significant difference between active and inactive groups ${ }^{*} p<0.05$. $\left.{ }_{39}=6.725, p<0.05 ; F_{2,39}=16.033, p<0.001\right)($ Table

$3)$. There were also significant interactions between the Group and Electrode location $\left(F_{2,39}=3.84, p<\right.$ $0.05)$. Post hoc tests showed that the P3 amplitude of the active group was larger than that of the inactive group at all electrode locations (Fig. 2). Moreover, post hoc tests showed that the active group exhibited an increased $\mathrm{P} 3$ amplitude at $\mathrm{Pz}$ compared with $\mathrm{Fz}(F$ $=15.52, p<0.001)$ and $\mathrm{Cz}(F=34.19, p<0.001)$ (Fig. 2). In contrast, the $\mathrm{P} 3$ amplitude for the inactive group was identical between $\mathrm{Fz}$ and Pz. Furthermore, post hoc tests showed that the $\mathrm{P} 3$ amplitude at $\mathrm{Cz}$ was significantly smaller than at $\mathrm{Fz}(F=15.19, p<0.001)$ and $\mathrm{Pz}(F=15.37, p<0.001)$ (Fig. 2).

\section{DISCUSSION}

We examined the effects of habitual moderate exercise on central information processing in older adults using the reaction time (RT) and $\mathrm{P} 3$ component of event- 


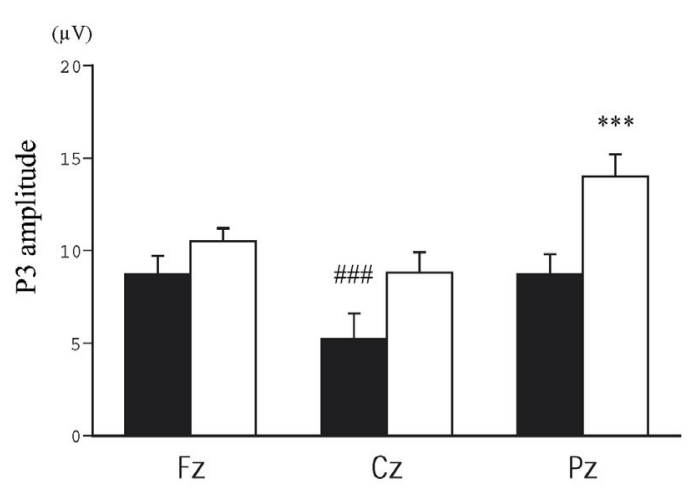

Fig. 2. Group (active, inactive) $\times$ Electrode location $(F z$, $\mathbf{C z}, \mathbf{P z}$ ) interaction for the $\mathbf{P} \mathbf{3}$ amplitude. The active older group is depicted by white bars, and the inactive group is illustrated by black bars. The active group exhibited an increased P3 amplitude at Pz compared to Fz and Cz $\left(^{* * *} p<\right.$ 0.001). In contrast, $P 3$ amplitude for the inactive group was identical between Fz and Pz, and P3 amplitude at $\mathrm{Cz}$ was significantly smaller than at $\mathrm{Fz}$ and $\mathrm{Pz}\left({ }^{\# \#} p<0.001\right)$.

related brain potentials (ERP). The exercise program in the present study consisted of various activities focused on enhancing the possibility of independent living. This involved movements important for everyday activities with demands on various physiological functions, such as aerobic capacity, muscle strength, and flexibility. The exercise intensity adopted in the present study corresponded to roughly $60-70 \%$ of the maximal heart rate during aerobic exercise and revealed an appropriated level required for enhancing aerobic capacity $[29,30]$. The active group had regularly partaken in an exercise program for more than three years. In contrast, the inactive group had no history of physical exercise.

The RT was faster for the active group than for the inactive group, which supports the findings that the capacity to react quickly is retained by older individuals who are physically active $[2,3]$. The present results are consistent with previous studies and suggest that habitual moderate exercise also promotes response processing in older individuals.

The P3 latency was no different between the active and inactive groups in this study. Dustman et al. [21] reported that the P3 latency tended to be longer for a low-fitness elderly group than for a high-fitness one. In contrast, Bashore [22] demonstrated a non-significant difference for shorter P3 latency in high-fitness elderly persons than in low-fitness ones. Hillman et al. [20] also failed to replicate the P3 latency results reported by Dustman et al. [21]. On the other hand, P3 latency is reasonably stable and varies relatively little as a function of task variables when the subject is engaged in an explicit discrimination task [31]. Thus, it is valid to conclude that $\mathrm{P} 3$ latency was no different between the active and inactive groups in this study.

In the present study, active older adults showed significantly higher P3 amplitude and faster reaction time than inactive ones. Kida et al. [32] found that the P3 amplitude was larger when the RT was fast and speculated that when more attentional resources were allocated to the given task, the motor outputs were faster. The present results support their findings and indicate that habitual moderate exercise affects both response processing and cognitive processing. Thus, exercise participation has consistently emerged as a key indicator of improved cognitive function [24, 33, 34]. Furthermore, a retrospective analysis found that behavioral stimulation and physical activity reduced the risk of developing Alzheimer's disease [35].

However, it is possible that the P3 amplitude is affected and changed by an arousal level or subject motivation. Polich and Kok [36] claimed that P3 is influenced by biological processes such as fluctuations in the arousal state of subjects. Kamijo et al. [37] examined the relationship between P3 and exercise intensity and suggested that changes in the $\mathrm{P} 3$ amplitude are an inverted U-shaped behavior of differences in exercise intensity. They reported that P3 amplitude might be influenced by the arousal state of subjects. Furthermore, long-term physical activity may enhance the arousal or motivation levels of older adults. In the current study, it is thought that these levels were almost the same between the active and inactive groups because the inactive individuals were new members of the exercise class and participated voluntarily before starting the class.

Moreover, we suggest that the exercise programs adopted in this study also affected the cognitive processing of active older individuals. Specifically, aerobic performance participants had to rhythmically perform upper- and lower-limb gymnastics to the sound of music. They needed to self-examine their movements and correct them by watching the educator's performance. Thus, the participants had to quickly transform various sensory inputs (e.g., auditory, visual, and somatosensory) into motor outputs and simultaneously needed to recall movement patterns. The repetition of sensori-motor processing, such as in our exercise programs, accompanied by motor learning may activate cognitive functions in older adults. Motor skill learning has been shown to increase cortical thickness and synaptogenesis [38], as well as the number of synapses per neuron in the cerebellum [39, 
40]. It is clear that voluntary exercise can increase levels of brain-derived neurotrophic factor (BDNF) and other growth factors, stimulate neurogenesis, increase resistance to brain insult, and improve learning and mental performance [41]. Moreover, van Praag et al. [42] found that physical activity increased cell proliferation, cell survival and neurogenesis in the hippocampus to improve hippocampus-dependent spatial learning. It has been reported that $\mathrm{P} 3$ occurs in the hippocampus and adjacent structures [43, 44]. On the basis of previous studies and the present findings, we suggest that long-term moderate exercise with motor learning may cause plastic changes to the hippocampus of active older adults and improve cognitive processing in comparison to inactive older individuals.

With regard to electrocortical patterns, the active group showed maximum P3 amplitude at Pz, and the $\mathrm{P} 3$ amplitude for the inactive group was identical between $\mathrm{Fz}$ and $\mathrm{Pz}$. Previous studies found a more frontal and equipotential P3 scalp distribution with increasing age in contrast to the parietal distribution in young subjects $[12,13]$. The inactive group showed a typically older P3 scalp distribution; however, the distribution of the P3 amplitude in the active group appeared predominantly at the parietal site and more closely resembled that found in younger adults. The P3 amplitude at $\mathrm{Cz}$ was the smallest in both active and inactive groups. This result depends not only on age-related changes in the scalp distribution of $\mathrm{P} 3$, but also on the readiness potential (RP) associated with button pressing. The RP starts about 1.5-2.0 s before the movement onset and is maximal at the mid-line vertex $(\mathrm{Cz})$ [45]. The generator source of the RP has been thought to include at least the foot area of the primary motor cortex [46] and of the supplementary motor area (SMA) [47], corresponding to the mid-line vertex $[\mathrm{Cz}]$. Therefore, the decline of the $\mathrm{P} 3$ amplitude at $\mathrm{Cz}$ might be caused by the superimposition of the RP. However, we conjecture that RP hardly affects P3 amplitude at $\mathrm{Pz}$ because the interstimulus interval (ISI) was not fixed and was of a relatively short duration. Moreover, the movement task consisted simply of button pressing, requiring little effort. We presume that the significant difference in $\mathrm{P} 3$ amplitude at $\mathrm{Pz}$ between active and inactive groups resulted from the effects of long-term moderate exercise.

The main findings of the present study are that older individuals who maintain moderate physical activity have improved reaction speeds in a somatosensory oddball task, and they also have improved
P3 amplitude relative to age-matched inactive peers. Specifically, the electrocortical patterns of activity in the active older group appeared to more closely resemble those of younger adults. In conclusion, habitual moderate exercise exerts a positive influence in older adults not only on response processing, but also on cognitive processing.

This research was supported by the Nishihira/Tsukuba Project of COE (Center of Excellence) from the Japan Ministry of Education, Culture, Sports, Science and Technology, and by a grant from the Japan Ministry of Education, Culture, Sports, Science and Technology (No. 14780003).

\section{REFERENCES}

1. Tanaka $H$ and Seals DR: Physiology of aging Invited review: Dynamic exercise performance in masters athletes: insight into the effects of primary human aging on physiological functional capacity. J Appl Physiol 95: 2152-2162, 2003

2. Spirduso WW: Reaction and movement time as a function of age and physical activity level. J Gerontol 30: 435-440, 1975

3. Spirduso WW: Physical fitness, aging, and psychomotor speed: a review. J Gerontol 35: 850-865, 1980

4. Colcombe SJ, Erickson KI, Raz N, Webb AG, Cohen NJ, McAuley E, and Kramer AF: Aerobic fitness reduces brain tissue loss in aging humans. J Gerontol A Biol Sci Med Sci 58: 176-180, 2003

5. Jernigan TL, Archibald SL, Fennerna-Noestine C, Gamst AC, Stout JC, Bonner J, and Hesselink JR: Effects of age on tissues and regions of the cerebrum and cerebellum. Neurobiol Aging 22: 581-594, 2001

6. Polich J: EEG and ERP assessment of normal aging. Electroenceph Clin Neurophysiol 104: 244-256, 1997

7. Kutas M, McCarthy G, and Donchin E: Augmenting mental chronometry: the P300 as a measure of stimulus evaluation time. Science 197: 792-795, 1977

8. McCarthy G and Donchin E: A metric for thought: a comparison of P3 latency and reaction time. Science 211: 77-80, 1981

9. Duncan-Johnson CC: P3 latency: A new metric of information processing. Psychophsyiology 18: 207-215, 1981

10. Wickens C, Kramer AF, Vanasse L, and Donchin E: The performance of concurrent tasks: a psychophysiological analysis of the reciprocity of information processing resources. Science 221: 1080-1082, 1983

11. Donchin E and Coles MGH: Is the P300 component a manifestation of context updating? Behav Brain Sci 11: 357-374, 1988

12. Goodin DS, Squires KC, Henderson BH, and Starr A: Age-related variations in evoked potentials to auditory stimuli in normal human subjects. Electroenceph Clin Neurophysiol 44: 447-458, 1978

13. Pfefferbaum AP, Ford JM, Wenegrat BG, Roth WT, and Kopell BS: Clinical application of the P3 component of event-related potentials. I: Normal aging. Electroen- 
Aging, Moderate Exercise and P3

ceph Clin Neurophysiol 59: 85-103, 1984

14. Narici M, Bordini $M$, and Cerretelli P: Effect of aging on human adductor pollicis muscle function. J Appl Physiol 71: 1227-1281, 1991

15. Short KR, Vittone JL, Bigelow ML, Proctor DN, and Nair $\mathrm{S}$ : Age and aerobic exercise training effects on whole body and muscle protein metabolism. Am J Physiol Endocrinol Metab 286: E92-E101, 2004

16. Windecker S, Allemann Y, Billinger M, Pohl T, Hutter D, Orsucci T, Blaga L, Meier B, and Seiler C: Effect of endurance training on coronary artery size and function in healthy men: an invasive followup study. Am J Physiol Heart Circ Physiol 282: H2216-H2223, 2002

17. Kraemer WJ, Hakkinen K, Newton RU, Nindl BC, Volek JS, McCormick M, Gotshalk LA, Gordon SE, Fleck SJ, Campbell WW, Putukian M, and Evans W: Effects of heavy-resistance training on hormonal response patterns in younger vs. older men. J Appl Physiol 87: 982-992, 1999

18. Hakkinen KW, Kallinen M, Linnamo V, Pastinen UM, Newton RU, and Kraemer WJ: Neuromuscular adaptations during bilateral and unilateral strength training in middle-aged and elderly men and women. Acta Physiol Scand 158: 77-88, 1996

19. Sherwood DE and Selder DJ: Cardiorespiratory health, reaction time and aging. Med Sci Sports 11: 186-189, 1979

20. Hillman $\mathrm{CH}$, Weiss EP, Hagberg JM, and Hatfield BD: The relationship of age and cardiovascular fitness to cognitive and motor processes. Psychophysiology 39: 303-312, 2002

21. Dustman RE, Emmerson RY, Ruhling RO, Shearer DE, Steinhaus LA, Johnson SC, Bonekat HW, and Shigeoka JW: Age and fitness effects on EEG, ERPs, visual sensitivity, and cognition. Neurobiol Aging 11: 193-200, 1990

22. Bashore TR: Age, physical fitness, and mental processing speed. Annu Rev Gerontol Geriatr 9: 120-144, 1989

23. Lucini D, Cerchiello M, and Pagani M: Selective reductions of cardiac autonomic responses to light bicycle exercise with aging in healthy humans. Autonomic Neurosci 110: 55-63, 2004

24. Rogers RL, Meyer JS, Mortel KF: After reaching retirement age physical activity sustains cerebral perfusion and cognition. J Am Geriatr Soc 38: 123-128, 1990

25. Colcombe SJ, Kramer AF, Erickson KI, Scalf P, MCcAuley E, Cohen NJ, Webb A, Jerome GJ, Marquez DX, and Elavsky S: Cardiovascular fitness, cortical plasticity, and aging. Proc Natl Acad Sci USA 101: 3316-3321, 2004

26. Harada T, Okagawa S, and Kubota K: Jogging improved performance of a behavioral branching task: implications for prefrontal activation. Neurosci Res 49: 325-337, 2004

27. American College of Sports Medicine: ACSM's Guidelines for Exercise Testing and Prescription, 6th ed, Lippincott W and Wilkins, Philadelphia, PA, USA, 2000

28. Vasey MW and Thayer JF: The continuing problem of false positives in repeated measures ANOVA in psychophysiology: A multivariate solution. Psychophysiol- ogy 24: 479-486, 1987

29. Larson EB and Bruce RA: Health benefits of exercise in an aging society. Arch Intern Med 147: 353-356, 1987

30. Puggaard L: Effects of training on functional performance in 6575 and 85 year-old women: Experiences deriving from community based studies in Odense, Denmark. Scand J Med Sci Sports 13: 70-76, 2003

31. Polich J: Attention, probability, and task demands as determinants of $\mathrm{P} 300$ latency from auditory stimuli. Electroenceph Clin Neurophysiol 63: 251-259, 1986

32. Kida T, Nishihira $Y$, Hatta A, Wasaka T, Nakata H, Sakamoto M, and Nakajima T: Changes in the somatosensory N250 and P300 by the variation of reaction time. Eur J Appl Physiol 89:326-330, 2003

33. Blomquist KB and Danner F: Effects of physical conditioning on information-processing efficiency. Perceptual Motor Skills 65: 175-186, 1987

34. Hill RD, Storandt M, and Malley M: The impact of longterm exercise training on psychological function in older adults. J Gerontol 48: 12-17, 1993

35. Friedland RP, Fitsch T, Smyth KA, Koss E, Lerner AJ, Chen $\mathrm{CH}$, Petot GJ, and Debanne SM: Patients with Alzheimer's disease have reduced activities in midlife compared with healthy control-group members. Proc Natl Acad Sci USA 98: 3440-3445, 2001

36. Polich $J$ and Kok A: Cognitive and biological determinants of P300: an integrative review. Biol Psychol 41: 103-146, 1995

37. Kamijo K, Nishihira Y, Hatta A, Kaneda T, Wasaka T, Kida T, and Kuroiwa K: Differential influences of exercise intensity on information processing in the central nervous system. Eur J Appl Physiol 92: 305-311, 2004

38. Kliem JA, Lussing E, Schwarz ER, Comery TA, and Greenough WT: Synaptogenesis and FOS expression in the motor cortex of the adult rat after motor skill learning. J Neurosci 16: 4529-4535, 1996

39. Black JE, Isaacs KR, Anderson BJ, Alcantara AA, and Greenough WT: Learning causes synaptogenesis, whereas motor activity causes angiogenesis, in cerebellar cortex of adult rats. Proc Natl Acad Sci USA 87: 5568-5572, 1990

40. Isaacs KR, Anderson BJ, Alcantara AA, Black JE, and Greenough WT: Exercise and the brain: Angiogenesis in the adult rat cerebellum after vigorous physical activity and motor skill learning. J Cereb Blood Flow Metab 12: 110-119, 1992

41. Cotman CW and Berchtold NC: Exercise: a behavioral intervention to enhance brain health and plasticity. Trends Neurosci 25: 295-301, 2002

42. van Praag $H$, Kempermann $G$, and Gage $F H$ : Running increases cell proliferation and neurogenesis in the adult mouse dentate gyrus. Nature Neurosci 2: 266-270, 1999

43. Halgren E, Squires NK, Wilson CS, Rohrbaugh JW, Babb TL, and Crandall PH: Endogenous potentials generated in the human hippocampal formation and amygdala by infrequent events. Science 210: 803-805, 1980

44. Okada YC, Kaufman L, and Williamson SJ: The hippocampal formation as a source of the slow endogenous potentials. Electroenceph Clin Neurophysiol 55: 


\section{A. HATTA et al.}

417-426, 1983

45. Kornhuber $\mathrm{HH}$ and Deecke L: Hirnpotentialanederungen bei willkurbewegungen und passiven bewegungen des menschen: Bereitschaftspotential und reafferente potentiale. Pflugers Arch 284: 1-17, 1965

46. Brunia CHM, Voon FJ, and Berger MPF: Movement-related slow potentials. II: A contrast between finger and foot movements in left-handed subjects. Electroenceph Clin Neurophysiol 60: 135-145, 1985

47. Ikeda A, Luders HO, Burgess RC, and Shibasaki $H$ : Movement-related potentials recorded from supplementary motor area and primary motor area: role of supplementary motor area in voluntary movements. Brain 115: 1017-1043, 1992 